the loge sucoeeded. Two formed of a very hrge sise in the hams, and the skin became so thin that I thought it would give way. The child, in threo days, becamo pallid and exsanguine, and her pulse very sharp and hemorrhagic. After using a mercurial purge, I at once resorted to the following mixture.

R Olei terebinth. 3 ss.

Olei ricini žj.

Mucilaginis,

Sacchari, àa, q. s.

Olei caryophyl. gtts. iv.

Aquæ dist. ad ऊ vij

Misce ut fiat mistura, cujus sumat cochlearia ij. vel iij. bis vel ter in die.

The effect of this mixture was most satisfactory. The purpuric spots rapidly disappcared, the bowels acted copiously and naturally, the appetite of the child became good, and the temper cheerful.

I certainly believe that in all passive hæmorrhages, turpentine will be found most valuable in its effects; and in this class of diseases we must generally place purpura.

Chesterfield, August 26th, 1953.

\section{GALLIC ACID IN THE TREATMENT OF PURPURA HAMORRHAGICA.}

$$
\text { By T. P. J. GIIANTH.AI, Esq. }
$$

Some years ago I lost one very dear to me from purpura hæmorrhagica: and my attention was thereby strongly directed to that disease, with the hope of discovering some more satisfactory mode of treatment.

The value of gallic acid in passive hæmorrhages induced me to give it a trial in purpura hæmorrhagica, and the results obtained were very gratifying. Moreorer, its safety, promptness, and pleasantness, are no inconsiderable recommendations of this remedy.

If the reader should not find any novelty in the application of gallic acid to this discase, the subjoined cases will at least confirm, as far as they go, the value of the treatment.

CASE I. Mr. E., a farmer and miller, aged 60 years, came under treatment on the 18th November 1852. Two days previously, he had noticed a soreness of the tongue, and perceived that the saliva was bloody. The symptoms of purpura were well marked. The gums were spongy, and they bled freely. The tongue and the buccal mucous membrane werc dotted with purple fungoid excrescences, some of which were as large as split peas, and from them blood cozed. The breath was offensive, and the appetite was impaired. The urine contained a considerable quantity of blood. Petechiæ were scattered over the thoracic and dorsal regions; and there was a large ecchymosis on one arm, and another on one of the thighs. The gallic acid was administered in five grain doses every three hours, and two compound rhubarb pills were given at bedtime. On the 20th, the purple excrescences had shrunken and ceased to bleed; the petechir and ecchymoses had faded; and the urine was free from blood. On the 30th, the improvement had been sustained. He was quite well again. He said that the first dose of medicine seemed to do him good. Only four scruples were taken.

CASE II. This was a more serious case, several days having elapsed from the first setting in of homorrhage from the nose before the patient came under my care. Master C., aged 16 years, a draper's apprentice, was seen by me on the 21st June 1853. He was greatly exhausted and blanched from epistaxis, hxmoptysis, melæna, hæmaturia, petechiæ, and ecchymoses. He was immodiately ordered to take gallic acid in doses of three grains every three hours, and subsequently in five grain doses every two hours. The pil. rhei comp. was given as an aperient. The treatment was followed by most marked benefit, and before a week had elapsed, all hæmorrhage had ceased. On the 5th July, a slight recurrence of epistaxis happened, oring to his haring too soon resumed sctive exercisa But the bleoding was quictly checked by a few dowes of the acid, and complete convalescence speedily followed.

CASE III. H. B., aged 12 years, son of an agricultural labourer, after three weeks illness from typhus, then prevalent in the village where he resided, was seized on the 16th August 1853, with hæmorrhage from the nose, gums, and bowels. The tongue was dotted with purple spots, and the back sprinkled with numerous small petechix. The treatment adopted was the same as in the former cases. On the 17th, hæmaturia was superadded to the other symptoms, which were very severe. On the 18th, the hæmorrhages began to abate. On the 20th, the spots on the tongue and the petechix had faded; the hæmorrhages had nearly stayed. On the 21 st, a severe return of epistaxis occurred, from picking his nose. This was followed by alarming prostration of strength. He was ordered to take the acid every hour, and to have his nose plugged. On the 22nd, all bleoding had ceased. On the 30th, I found that there had been steady and daily improvement since last report. On the 31st, he was convalescent.

This was a severe case, as the patient's strength had been so much reduced by a previous exhausting disease ; and, accordingly, it was necessary to push the acid to a considerable extent.

In all the cases the dietetic and general management were carefully attended to.

Burgh-le-Marsh, J.incolnshire, Sept. 1st, 1853.

\section{ON FEVER IN RURAL DISTRICTS.}

By W. VINER BEADLE, M.D.

Is recent numbers of the Association Jodrnal, I find reports of discussions at the Epidemiological Society, on different kinds of fevers. On a subject of such importance I venture to break the seal of silence, the "sigilla grata pudico", and to offer the following remarks on the Fevers of Rural Districts, as I have myself observed them.

My own impression is, that all the true fevers are closely connected with one another in origin and nature; that certain endemic even more than epidemic causes may produce these; but that, once brought into existence, they may under certain circumstances, only moderately favourable, be propagated; but that, these favouring circumstances being removed, they sink for want of their proper pabulum.

I, therefore, fully agree with the remarks of Dr. Southwood Smith, that "ferer is no doubt capable of extinction. The old fevers are now unknown; and were the earth cultivated like a garden, and the people all rational beings, it would soon cease." New modified forms, it is true, may arise of the same type, and yet bear no further comparison than does our present newt to the icthyosaurus of geologists.

On looking at the number of deaths by typhus in the Registrar-General's report for 1842 , I find it to be 16,201 , of which a large proportion occurred in country districts. It is to this latter class that I now more especially refer.

Amongst the circumstances which I recognise as the most favourable to the development of typhus fever, are-

1st. The nouveau séjour of Broussais, in places where the resident inhabitants are little affected.

2nd. (a) The want of drainage and ventilation; (b) human effluvium concentrated; (c) damp and consequently a cold and depressing neighbourhood and soil.

3rd. Though in a less degree, infection from those already affected, if also exposed to the same polluting influences.

Such is my impression of the origin of our fevers; and such causes must be efficiently removed ere fevers will vanish. I do not mean to speak dogmatically, since I am happy to say that my experience is comparatively limited; though even the cause of that limitation is not without a bearing on the subject. "Many years ago", remarked a gentleman to me, "fever always raged here towards the autumn; and many who were able felt great anxiety to escape at that time from the town." Now, however, since 